\title{
EL DOBLE VÍNCULO COMO IMAGEN DE MUNDO EN LA NAVE DE LOS LOCOS DE CRISTINA PERI ROSSI
}

\author{
Cristián Cisternas Ampuero \\ Universidad de Chile, Santiago de Chile, Chile \\ ccistern@uchile.cl \\ Patricia Valenzuela Tapia \\ Universidad Autónoma de Chile, Santiago de Chile, Chile \\ pvpatita443@gmail.com
}

\begin{abstract}
RESUMEN / ABSTRACT
Este artículo se centra en el concepto de "doble vínculo", aplicado a la novela contemporánea $L a$ nave de los locos (1984), de Cristina Peri Rossi. Se plantea que este concepto, proveniente de la psiquiatría, ayuda a comprender la imagen de mundo de angustia y dislocación que rodea a los personajes. Se propone también una posibilidad de escape frente a esta condición existencial.

Palabras clave: Cristina Peri Rossi, literatura latinoamericana, siglo XX; La nave de los locos, crítica e interpretación; teoría del doble vínculo.
\end{abstract}

\section{The Double Bind as World Image in La NaVe de los locos by CRISTina Peri Rossi}

This article deals with the concept of "double bind", as applied to La nave de los locos (1984), a Latin American contemporary novel by Cristina Peri Rossi. I argue that the psychiatric notion of "double bind" helps to understand the image of a world of anguish and dislocation that surrounds the characters. Moreover, this article proposes a possibility of escape from this existential condition.

KEYWORDS: Cristina Peri Rossi, Latin American Literature, Twentieth Century, La nave de los locos, criticism and interpretation. Double Bind Theory. 
"Los hombres sabios ven contornos y por consiguiente los trazan".

W. Blake

"En la vida que vivimos, nuestras percepciones son, tal vez siempre, percepciones de partes, y nuestras conjeturas acerca de las totalidades son corroboradas o refutadas de continuo por la presentación posterior de otras partes. Tal vez sea por esto que las totalidades nunca puedan ser presentadas, ya que ello implicaría una comunicación directa".

G. Bateson

"Haciendo formas en todo el derredor, nada se irá jamás.

J. Emar

\section{INTRODUCCIÓN}

La nave de los locos (1984), de Cristina Peri Rossi (1941), es una novela que se estructura sobre la narración enmarcada ${ }^{1}$ de los viajes de un protagonista llamado Equis, arquetipo del sujeto contemporáneo errante, quien emprende un viaje que se define como "el viaje incesante, la gran huida, la hipóstasis del viaje"(Peri Rossi 33). Este periplo se presenta como la desmitificación del viaje mítico del héroe ${ }^{2}$, al quedar su desenlace abierto, e incierto el regreso del héroe a sus lares. También se caracteriza por la enunciación de múltiples narradores y por la disposición fragmentaria de la novela. Por otra parte, La nave de los locos representa y discute condiciones culturales que constituyen una imagen de mundo caracterizada por la violencia de género, la deshumanización urbana, la persecución política, la nostalgia por una legalidad de mundo premoderna y las alteridades sexuales. Todos estos niveles de composición implican un complejo ensamblaje de la mímesis, su exhibición como diégesis (artificio) y metáfora de un mundo real-referencial

1 En un sentido amplio y trascendente: el marco narrativo básico es la representación del Tapiz de Gerona que alguien (podemos conjeturar, el protagonista de la novela, Equis) se encuentra contemplando. El marco narratológico está provisto por lo que llamo el Narrador (III), y que explicaré más abajo.

En el sentido que quedó establecido en el estudio definitivo de Joseph Campbell, El héroe de las mil caras. Dicho viaje consiste de una serie de etapas iniciáticas que incluyen la partida, la iniciación y el regreso, cerrándose el ciclo con la transformación del héroe. En muchas novelas contemporáneas este viaje de formación queda incompleto, o se vacía de sentido, o es parodiado. Ver, El héroe de las mil caras, psicoanálisis del mito. 
en que coexiste una constelación de sucesos y actividades cotidianos u ocultos (por ejemplo, la vida en la ciudad y la sobrevivencia en los campos de concentración). Por encima de todo, está una visión o legalidad de mundo (Weltanschauung) ${ }^{3}$ que se caracteriza por mandatos contradictorios, confusiones identitarias, alternancia de estados de conciencia y condiciones existenciales en las que el sujeto moderno se encuentra atrapado en lo que he llamado "doble vínculo", es decir, una condición del existir moderno en que se deben aceptar (e introyectar) contradicciones lógicas para poder seguir existiendo sin perder la razón ${ }^{4}$.

La nave de los locos es una novela que plantea la circunstancia de un viajero lector que debe lidiar con un contexto cultural que propicia el funcionamiento de las situaciones de doble atadura. Crisis existencial de identidad; inconsciente manifestándose a través de sueños; memoria llena de eventos traumáticos y su condición de extranjeridad en un mundo en que la globalización de la experiencia ha vuelto fútil la vivencia del viaje, amenazando la estabilidad de la identidad misma del sujeto ${ }^{5}$. La experiencia estética del viajero lector "Equis", proyectada sobre obras de arte, sobre la belleza de la mujer (por ejemplo, la actriz Julie Christie), sobre el cine, etc., se realiza como una estrategia de supervivencia frente al doble vínculo, en que la autonomía del sujeto se alcanza a través de un cruce de límites cognitivos

3 Sobre una visión actualizada del concepto "Weltanschauung", se puede consultar el artículo de Marcel Cano et al. "La Weltanschauung (cosmovisión) en el comportamiento medioambiental del siglo XXI: cambios y consecuencias”. En: Ludus Vitalis, Vol. XVIII.

Para precisar el concepto, cito la formulación del psiquiatra Ronald Laing: "Una persona comunica a otra que debe hacer una cosa y al mismo tiempo, pero en otro nivel, que no debe hacerla o que debe hacer otra cosa incompatible con la primera. Esta situación tiene su remate para la "víctima" en la imposición ulterior de una posición 'insostenible' en la cual no puede hacer un solo movimiento sin que sobrevenga la catástrofe" (...). Finalmente, una vez que la víctima ha aprendido a percibir su universo bajo las pautas de la doble atadura, la serie completa de ingredientes deja de ser necesaria. Y entonces casi cualquier parte de cualquier secuencia de doble atadura puede ser suficiente para precipitar el pánico o la furia". Laing, R. D. El yo y los otros.

"En la esquizofrenia se produce un bloqueo de la capacidad de establecer e identificar patrones de comunicación y el doble vínculo consiste en perpetuar situaciones contradictorias que niegan el principio de identidad. En general, todos somos víctimas de este tipo de comunicación, pero algunos no tienen la capacidad de discriminar el verdadero significado del mensaje en el que se mezclan estados de ánimo, proyectos, contexto y la relación que existe entre los que se están comunicando". En: http://psicologia.laguia2000.com/la-familia/ teoria-del-doble-vinculo. Consultado en abril de 2017. 
que modifican la percepción de la realidad y la autopercepción, desvelando el absurdo del mundo y sus contradicciones no resueltas, por ejemplo, a nivel político, de género, etc.

En La nave de los locos hay diversos planteamientos asimilables al doble vínculo; frente a la norma bíblica de crecer y multiplicarse, basada en la condición primordial de fecundidad atribuída a Eva, surge la condenación del sexo fuera del matrimonio y, al mismo tiempo, se propone el aborto como norma social a la vez necesaria y culpable, y, de ahí, la incorporación de la culpa en las mujeres que conoce Equis en Londres. Ante el mandato original que surge en el sueño de Equis, "a la ciudad que llegues, descríbela" (Peri Rossi 9), se opone la condición de extranjeridad eterna del protagonista ${ }^{6}$, que le impide conocer el "alma" de cada ciudad", pero que le permite (siempre con culpa) delegar la tarea en otro personaje, el excéntrico Morris. La legalidad de mundo que condiciona a los protagonistas es básicamente paradojal; los mensajes y prácticas contradictorios que los rodean inducen la tristeza, la desesperación y la angustia ${ }^{8}$.

De más está decir que la noción de doble vínculo como metáfora de la concreción estético-literaria dice relación con la posición "insostenible" en que el lector mismo es puesto, no solo en La nave de los locos, sino en toda obra literaria contemporánea, cuando debe resolver mensajes contradictorios entre el texto y el mundo, entre la enunciación literal y la dicción irónica, o entre lo verosímil real-referencial y lo verosímil puramente ficcional. Así, la referencia al Tapiz de la Creación de la Catedral de Gerona (cuya descripción

6 "Soy un hombre sedentario - dice Equis-. Sin embargo, me he visto obligado a viajar de manera casi permanente, de modo que puede decirse que los viajes son mi segunda naturaleza" (Peri Rossi 175).

La expresión "alma de la ciudad" se debe al historiador alemán Oswald Spengler. Ver: La decadencia de Occidente (Der Untergang des Abendlandes (1918).

"La Escuela Psicosocial de Palo Alto retoma a través de la teoría del double bind la noción tradicional de paradoja. Su mayor aportación es el hecho de haber conseguido que la paradoja no se considere desde un punto de vista formal-sintáctico sino fundamentalmente pragmático (...) Fue el sobrino de Wittgenstein, Heinz Von Foester, quien trasladó la paradoja a la praxis de la ciencia experimental, extendiéndola a casi todos los aspectos del fenómeno humano: a los problemas de la percepción, de la cognición y de las otras funciones del sistema nervioso, de la inteligencia artificial, de la biofísica y sobre todo del concepto de la autoorganización de los sistemas (autopoiesis)". Cito por Parrilla, Desiderio, "René Girard y la teoría del doble vínculo de Palo Alto". En: Revista de Filosofía, Vol. 2, 2015. Disponible en: https://revistas.ucm.es/index.php/RESF/article/download/50058/46532. 
se presenta fragmentariamente a lo largo de la novela) se establece como antecedente referencial que el lector real no puede ignorar; por otro lado, la descripción (y ficcionalización) del mismo nos libera, temporalmente, de la necesidad de ver, físicamente, alguna reproducción del Tapiz, o al Tapiz mismo. Finalmente, la sobredeterminación de este elemento a lo largo de la obra lleva al lector real a la conclusión de que sí debe familiarizarse con el Tapiz para integrarlo a una lectura interpretativa más profunda de la novela ${ }^{9}$.

Cabe destacar que la teoría del doble vínculo admite, a su vez, una doble interpretación, ya sea como descripción de un patología socialmente inducida o de un estado cognitivo individual, caracterizado por una extrema lucidez en relación con la articulación de los sistemas de interacción que nombran la realidad y la tipifican. El hecho, pues, de que el doble vínculo aparezca relacionado con la discusión sobre la esquizofrenia, no desmerece la posibilidad de que su verbalización (el testimonio de un sujeto atrapado en una situación insostenible $y$ consciente de ello) y consiguiente comunicación trascienda los límites de la terapia y se convierta en discurso pragmáticamente construido, enunciado y percibido estéticamente ${ }^{10}$.

A continuación, propondré que La nave de los locos puede ser leída como un diagnóstico de una condición humana extremada y limítrofe, a saber, un estado de confusión original de la identidad (que pasa por el lenguaje y las lenguas) y de la finalidad del ser-sujeto (de su proyecto que les es propio). La entidad supra-narratorial, que he identificado como Narrador (III), viene a ser el demiurgo que exhibe la arquitectura defectuosa del sistema de

$9 \quad$ Sobre el Tapiz de la Creación o Tapiz de Gerona se puede consultar: Lamberto Font Gratacòs, "El tapiz de la Creación de la Catedral de Gerona: ensayo de estudio para una monografia". En: http://dugi doc.udg.edu/bitstream/handle/10256/5970/53330.pdf?sequence=1. Consultado en abril de 2017.

10 Morin destaca que la categoría de bucle recursivo constituye "una noción esencial para concebir los procesos de auto-organización y autoproducción". Desarrollada en el marco del pensamiento cibernético (Ashby 1962; Foerster 1960), la auto-organización apunta a la generación y producción de un orden emergente sin un organizador o control centralizado. La auto-organización parece ser una cualidad de un conjunto muy amplio de sistemas, por ejemplo, los sistemas vivientes (Maturana \& Varela 1972), los mercados económicos (Hayek 1964), las colonias de hormiga o el comportamiento de otros animales sociales (Bonabeau, Dorigo \& Theraulaz 1999), las redes neuronales del cerebro ( Johnson 2001) y los sistemas sociales (Luhmann 1998; Sawyer 2005), entre otros fenómenos. Cito por: Rodríguez-Zoya, L. G. y Rodríguez-Zoya, P. G. "El doble vínculo entre representaciones sociales y comunicación social". 
interacción humana, delegando en voces narrativas subsidiarias la mostración de secuencias de "doble atadura" que afloran tanto en la historia como en el nivel del lenguaje o a la trayectoria existencial y axiológica reflejada por los actantes. La noción de "doble vínculo", redefinida, ahora, como una modalidad de existencia que, en su condición fronteriza de convivencia de discursos simultáneos y contradictorios, mantiene al sujeto en constante diferenciación de sus opciones de naturaleza, sin permitir que cristalice ninguna, tiene el valor de proceso de semiosis ${ }^{11}$ que opera en los tres principales niveles del texto (historia, enunciación y personajes), dándole forma y diferenciándolo definitivamente ${ }^{12}$.

\section{LA HISTORIA: EL MANDATO DEL VIAJE.}

En La nave de los locos, el mandato inaugural que el personaje Equis recibe en sueños, aparece como antecedente de una condición humana de existencia ya degradada por la confusión de una premisa primera: el habitar como humanos sobre la tierra (la condición de trabajar la tierra se complica por la maldición bíblica y la dificultad para separar "la paja del grano").

En el sueño, recibía una orden. "La ciudad a la que llegues, descríbela". Obediente, pregunté: “¿Cómo debo distinguir lo significante de lo insignificante?" (...)" Trabajaba en silencio, hasta que ella apareció. Inclinada sobre el campo, tuvo piedad de una hierba y yo, por complacerla, la mezclé con el grano. Luego, hizo lo mismo con una

\footnotetext{
11 Entenderé "semiosis" en el amplio sentido que le otorga Patricia Cordella: "La semiosis en los seres vivos es una experiencia continua automática e irrenunciable que convierte señales detectadas por los receptores de este organismo en significado. Esta conversión hace que la señal sea tomada en cuenta por ese organismo según los convenios que la comunidad que lo articula haya acordado. Estos pactos -del-hacer y sentir- integran la historia de esa comunidad, los deseos y las necesidades de la misma. La ontogenia va ocurriendo dentro de este flujo del devenir evolutivo. Dicho de otro modo, la historia del individuo se despliega con las restricciones que el significado otorga a las señales que capta de los otros individuos, el medio o sí mismo”. (En: Patricia Cordella, ¿Qué es semiosis?”).

12 Juan Hidalgo (Universidad de Concepción) plantea una propuesta semejante a la mía: "Son tres los flujos fundamentales de exploración en la novela, propuestos por cada uno de los tres epígrafes: el viaje, el tapiz de la creación y la locura, en el marco del paratexto mayor, su título. En este sentido la novela nos hace una invitación a retener solamente lo que incrementa el número de conexiones". En: Co-herencia.
} 
piedra (...) Cuando se fue, quedé confuso (...) la duda me ganó (Peri Rossi 9).

Dicha confusión, y su consiguiente sentimiento de culpa y de aislamiento, viene siendo introducida por un principio femenino (Eva), en un marco remoto y no histórico, resolviéndose, a manera de reproducción especular, hacia el final de la novela, cuando Lucía, la joven bailarina, le ofrece a Equis el espectáculo que disuelve la pauta racionalista que opone géneros y sexos: la "paja" y el "grano". La confusión, introducida por la caridad de la mujer, entorpece el proceso semiótico, que define los orígenes de la cultura en el escenario mítico: la separación de lo significante de lo insignificante. Pero, además, corta la comunicación del ser creado con su Creador: “(...) y la voz ya no responde" (Peri Rossi 9).

Por otro lado, el mandato del viaje, comunicado al sujeto en el contexto del sueño por una voz indeterminada, imperativa, determina el proyecto de la existencia de Equis, el protagonista; su fuerza persuasiva, sin embargo, se ve seriamente amenazada por el resultado parcial de la confusión de pauta: la $d u d a$, primer paso hacia la condición des-realizadora que precede al desmantelamiento del doble vínculo ${ }^{13}$. Pese a ello, como veremos, dicho mandato persiste en su efecto siendo internalizado por el sujeto como primer eslabón de la secuencia misma del viaje: para describir una ciudad, hay que viajar hasta ella. Pero el viaje del exiliado es un viaje degradado desde el principio, una parodia de viaje; una diáspora forzosa.

Por otro lado, nuestro mandato primero aparece denegado por un mandato segundo que atribuye al viajero la condición de extranjeridad como un rasgo adicional de la condición bíblica de la confusión:

Extranjero. Ex. Extrañamiento. Fuera de las entrañas de la tierra. Desentrañado. Vuelto a parir (...) ¿Alguien, acaso, sabía cómo se encontraba el alma del extranjero? (...) Tenía alma el extranjero? Ya

13 Uso los conceptos de "realización”, “desrealización” y "rerrealización” en las acepciones que le da Ronald Laing. Cito: "Arrancar al propio Yo de la falsa sensación de realidad supone una desrealización de lo que falsamente se toma como realidad y una rerrealización de lo que falsamente se toma como irrealidad. Únicamente entonces se es capaz de apercibir el sistema de fantasía en que se está. El estado de cosas normal, empero, es hallarse tan hundido en la propia inmersión en los sistemas de fantasía social que se los toma por reales" (Laing 36). (Las cursivas son del autor). 
que extranjeros fuisteis en la tierra de Egipto (Peri Rossi 10; cursiva en el original).

En efecto, carente de un punto de referencia absoluto, de un origen que ha perdido en algún punto del periplo, el viajero Equis se verá enfrentado a la imposibilidad de conocer el "alma" de las ciudades por su condición misma de extranjero, de sujeto que no conoce la lengua ni las idiosincrasias de los lugares a los que llega. Su condición se asimila a la de los israelitas en Egipto (Libro de Éxodo 22: 21), amplificada por la alegoría moderna de la Nave de los $\operatorname{Locos}^{14}$ y por la condición contemporánea del exiliado que se desplaza de ciudad en ciudad, sin arraigar en ninguna. La desmedrada condición de Equis contrasta con la del excéntrico personaje llamado Morris, quien sobrevive en una isla, lejos de la ciudad, dejando de lado cualquier afán de habitar en la metrópolis y aplicando, por el contrario, una pauta lúdica (y ansiosa) para aproximarse a ella. Así, para enfrentar la angustia de aproximarse a la ciudad, Morris escribe un:

Manual práctico para extraviarse en la ciudad. Manual de circulación. Manual de paseos públicos. Instrucciones para evitar el cáncer. Cómo aprender alemán en diez lecciones. Esta obra trata del todo. Del enorme todo y sus diversa partes. O sea: del todo minimizado (Peri Rossi 128).

Llama la atención el mecanismo que ha permitido al excéntrico hacer productiva la confusión de niveles (míticos, políticos, discursivos) que rige en el mundo contemporáneo. En una cierta manera, Morris ha resuelto el mismo problema que se le ha planteado a Equis, verbalizando - escribiendo-la ausencia de puntuación semántica, constituyéndose él mismo en puntuador ${ }^{15}$ del "enorme todo" (la ciudad), que aparece, así, transfigurado en su esencia y reducido a una dimensión proporcional a la perspectiva del sujeto: un "todo

14 En el cuerpo de la novela de Peri Rossi, La nave de los locos aparece como referencia a la obra satírica de Sebastián Brandt, Das Narrenschiff, (1494), así como al cuadro de El Bosco, pintado aproximadamente entre 1504-1505.

15 La condición de "puntuador" de Morris está marcada por un indicio interesante: es coleccionista. Habita en una isla, Pueblo de Dios; su casa es de piedra "con pocas puertas y ventanas (...) con un enorme jardín delantero, invadido por los árboles, las hierbas y malezas (...) (Peri Rossi 99). Vemos que Morris reúne características propias del ermitaño, por oposición a Equis, el extranjero errante. 
minimizado" ${ }^{16}$. De todas maneras, Morris ha escapado al doble vínculo, eliminando la distancia entre el Yo y el Mundo gracias a su situación envidiable de que Equis (viajero) solo alcanzará luego de empaparse del sinsentido de los mensajes contradictorios que lo rodean.

Vale la pena comparar las secuencias actanciales de Equis y de Morris. Mientras a este último lo encontramos cuando ya se ha asentado en una isla $\mathrm{y}$, con ello, puesto fin a la condición de vagancia (que validaba, en círculo vicioso, su atribución de extranjeridad), el relato exhibe las múltiples vacilaciones de Equis que lo conducen, a través de alternativas de ensayo y error, a la plenitud final que le otorga la respuesta del enigma (la superación del doble vínculo).

Si se pudiese representar gráficamente el viaje de Equis, e interpretar dicha forma, se encontraría una semejanza con el movimiento de un "diente de sierra", que avanza, retrocede, desgasta y vuelve a avanzar un poco, siempre con gestos incidentes, nunca directos. De ahí que Equis viva su propio periplo como la recurrencia circular de un viaje leído y no vivido, es decir, despersonalizado y sometido a un proceso semiótico que genera el efecto del artificio y el cliché. Toda la secuencia de la relación con la Bella Pasajera abunda en referencias a una imagen cliché de la seducción en que la mujer es el agente ${ }^{17}$. El escenario (un viaje en barco), la música (sentimental, incluyendo a Los Panchos), la caracterización de la mujer, confluyen en la despersonalización de la experiencia: “Cuando ella cerró la puerta y comenzó a quitarse el vestido, sin haberse despojado antes de los zapatos, él pensó que eso también ya lo había leído" (Peri Rossi 16).

16 Sobre la noción de "puntuación semántica”, cito a Paul Watzlawick: “(...) Aggigeró quindi la questione del perché é necessario punteggiare, cioé, imporre un ordine o Gestalt sulle sequenze di evento circondano e concernono ogni essere vivente, e rileveró semplicemente l'ovvio: senza quest' ordine il mondo apparirebbe davvero casuale, cioé, caotico, imprevedibile ed extremamente minaccioso. Gli psicología della Gestalt hanno demostrato (...) che questo ordinamento é radicato negli strati piú profondi nella neurofisiología delle nostre percezioni, e il suo efetto si puo seguire da qui fino al nivelli piú alti del funzionamento umano, per esempio, la attivitá creative e l'umorismo" (Watzlawick 63).

17 Habiendo dirigido unas tesis de pregrado sobre este tema, recomiendo, para el motivo del amor, el trabajo de Constanza Richards Varas, "la desmitificación del tópico del amor en La nave de los locos. Santiago de Chile, 2014. Accesible en: http://repositorio.uchile. cl/bitstream/handle/2250/129727/La-desmitificacion-del-topico-del-amor-en-la-nave-de-loslocos.pdf?sequence $=3$ 
Y es precisamente la recurrencia de esta experiencia, marcada por el mandato de descripción (subconsciente) y su consiguiente negación en un segundo nivel (diégesis: condición de extranjeridad) como una flagrante contradicción, la que clausura toda expansión del sujeto. Un ejemplo de esta cerrazón lo observamos en la autocomplacencia que encuentra Equis en la contemplación reiterada de su deseo en la pantalla de un cine, única forma de encontrar el consuelo para su neurosis de extranjero eterno:

Los años que le faltan (...) Equis quisiera pasarlos sentado en la butaca del cine Rex, función continua, contemplando (...) las evoluciones de Julie Christie en la pantalla (Peri Rossi 22) ${ }^{18}$.

Puedo suponer que las secuencias circulares de comportamiento (de las cuales el doble vínculo es solo un ejemplo) generan a la larga, neurosis o atrofia del sujeto por la sola recurrencia de sus instancias, pues (copias infieles de otros sistemas cibernéticos existentes en la naturaleza) no consideran la opción de una autorregulación y autoevaluación del sujeto que las vive. En el caso de Equis, su imposibilidad de escapar a la fantasía ${ }^{19}$ de la extranjeridad radica en su propia lectura de la fantasía como una legalidad inamovible, semejante al teatro: un continuo de roles y escenas que se suceden con ligeras variaciones y que aportan una connotación de refugio: "El teatro es como un viaje sin traslado. He recorrido mundos sin moverme de mi butaca" (Peri Rossi 174).

Esta fantasía que reconcilia al viaje incesante con la inmovilidad aparece como naturalización de cualquier conducta desviacionista, es decir, como respuesta neurótica frente a la contradicción existencial. Para Equis, la experiencia del teatro es angustiosa, pues le sugiere la condición de estar atrapado en un laberinto de espejos, una "posición insostenible":

18 La película aludida en esta parte de la novela es Demon Seed(1977), protagonizada por Julie Christie, dirigida por Donald Cammell.

19 Ronald Laing cita la definición de "fantasía" de Susan Isaacs: "Las fantasías son el contenido primario de los procesos mentales inconscientes". Luego, Laing agrega que "las fantasías se experimentan como representaciones dramáticas" (Laing 16-17). En general, cuando este autor habla de "fantasía social", está sugiriendo que los pactos y compromisos sociales (especialmente, los que definen los conceptos de "norma" y "normal", también tienen un origen fantasmático, irracional, que puede ser desvelado y del cual podemos liberarnos. Así, citando a E. Jacques: "Todos estamos expuestos a ser arrastrados en sistemas de fantasía social, con pérdida de la propia identidad en el proceso, y sólo retrospectivamente nos damos cuenta de que eso ha ocurrido" (Laing 36). 
No es raro que los hombres que han inventado el teatro como un simulacro de la vida a su vez tengan pesadillas con el teatro, multiplicando así el juego de espejos: sueño que represento y en la representación a veces estoy dormido (Peri Rossi 173).

Como lo percibe otro personaje, Lucía, una de las mujeres abortadoras, el precio de forzar esta legalidad que impone el doble vínculo (tan vasta y apenas conjeturable de manera consciente, que solo se la puede nombrar como "azar") es la culpa:

Miles de condones diarios de los cuales se desliza una gota imperceptible. Para continuar la cadena del azar. La rompemos con un angustioso sentimiento de intervención, de haber transgredido sus normas ocultas, como la serie de oraciones y súplicas codificadas que debemos ofrecer, a cambio de un favor de la divinidad (Peri Rossi 174).

No resulta extraño, pues, que el lema que rige las secuencias vitales de Equis y de otros personajes sea el de "No están previstas expansiones". Tales expansiones implicarían la rotura de la secuencia circular, la posibilidad de lo desconocido, un encuentro con otros órdenes o con la ausencia de estos. Quizás si el mérito más grande del sistema de fantasía social ${ }^{20}$ en el que se "insertan" Equis y Lucía sea el de presentar la desviación como indeseable; hasta el último momento de la novela, Equis aspirará a encontrar su espacio habitable dentro del sistema, al interior de una ciudad cualquiera.

Pese a todo, la visión última del andrógino encarnado por la muchacha Lucía provee a Equis de un indicio para romper la circularidad de este sistema que se sustenta en el doble vínculo. Puede llamarse a esta visión una experiencia del contorno, del borde o del límite. Ya hemos visto que el mandato inicial dispone, para el sujeto, un proyecto que lleva en sí mismo la semilla del fracaso. De la misma manera, el doble vínculo opera en el nivel de los sueños de Equis; aquí la doble atadura se reedita como una revelación insoportable, que llena de culpa (por ejemplo, a Equis cuando viaja a Londres con las mujeres abortadoras) al sujeto que no estaba preparado, de ningún modo, para recibirla. Ambas situaciones se despliegan en secuencias

20 Calificar a este sistema como capitalista, totalitario o postmoderno es cuestión de opinión. En todos los casos, el sistema cultural y social se fundamenta en mandatos y tabúes que se contradicen con otros mandatos y tabúes secundarios que inducen en los sujetos elecciones que los atrapan en situaciones de resignación, de confusión o angustia. 
circulares que tienen como estado puro el dramático ejemplo del astronauta Gordon. La única opción para superarlas reside en la denuncia simultánea, por contigüidad, de los discursos contradictorios, re-nivelando la imposición secundaria (no romper la pauta) con el mandato primario: generar una pauta dentro de otra pauta (pero, para hacer esto, hay que romper la pauta, es decir, la dependencia del doble vínculo). La presentación del andrógino ${ }^{21}$ por parte de Lucía cumple con esta condición:

Descubría y se desarrollaban para él, en todo su esplendor, dos mundos simultáneos, dos llamadas distintas, dos mensajes, dos indumentarias, dos percepciones, dos discursos, pero indisolublemente ligados, de modo que el predominio de uno hubiera provocado la extinción de los dos (Peri Rossi 195).

La contemplación final del andrógino (antiguo símbolo de sabiduría hermética, emblema de la reconciliación de la naturaleza humana escindida) provee, finalmente, la clave para el enigma que, a la manera de un metacomentario que descontextualiza el discurso del doble vínculo, ha guiado, como una señal de emergencia lanzada por el subconsciente, el proceso de des-realización de Equis. Resulta provocativo que sea un pornoshow, es decir, una fantasía hiperrealista que pone en escena los roles y funciones eróticos que la sociedad no admite como posibles o simultáneas. Es así como el espectáculo de Lucía (cuya simultaneidad de discursos aparece imitada por una doble y reflexiva disposición tipográfica) (Peri Rossi 191) denuncia como irrelevantes los extremos de identidad, masculino y femenino, generando una revelación:

(Equis) era consciente de que la belleza de uno (el efebo Lucía) aumentaba la del otro (Dolores del Río), fuera el que fuera. (...) la revelación era casi insoportable. Impregnaba todas las cosas. Pero delante de ella, sólo cabía ser humilde (Peri Rossi 195; paréntesis míos).

El viaje imposible, la hipóstasis del viaje, es vuelto a contextualizar en el mundo onírico. La finalidad del viaje, describir, se transforma en solucionar un enigma que ronda en el subconsciente de Equis. La respuesta empieza por

21 Sobre el tema del andrógino, consultar: Cristina Valdivia, "La presencia del mito del andrógino en La nave de los locos de Cristina Peri Rossi”. En: Anuario de Pregrado, Universidad de Chile, 1. 
la sospecha de que quizás las premisas son capciosas. Antes de la pregunta por el viaje, que presupone la condición de extranjeridad, Equis concibe que el enigma ("¿Cuál es el mayor tributo, el homenaje que un hombre puede ofrecer a la mujer que ama?" (Peri Rossi 163) apunta a otra cosa, a la aceptación de una condición alternativa:

En el sueño, no consigo saber la respuesta (...) Se me ha ocurrido que quizá el enigma encierra un equívoco, tendiera una trampa, y la respuesta fuera: No hacer nada. Pero estaba equivocado (...) Es curioso: la respuesta estaba en mí desde hace tiempo, pero en el sueño no me animaba a pronunciarla. Porque seguramente es a la princesa a quien debo dársela primero, puesto que ella ha inspirado el enigma. De modo que si tú recibes la contestación adecuada, yo me habré liberado de la opresión (Peri Rossi 196).

La experiencia del contorno, que supera las oposiciones ortodoxas que separan lo significante de lo insignificante, puede caracterizarse como un desmantelamiento del Yo en tanto que perspectiva atribuida ${ }^{22}$. El sujeto no puede ser mentado en su naturaleza y en su esencia por ningún discurso, ya que es (se convierte en) una opción vacante, un signo cero; ya no es necesario describir la ciudad, o al otro, o al vínculo que me une a ellos, porque la ruptura del doble lazo me ha librado a una condición "otra" del ser. Resulta significativo que el texto guarde silencio sobre el destino final de Equis; quizás su nueva posición está más allá de toda referencia. De una cosa sí podemos estar seguros: para él ya no habrá viajes ni reposos, tal vez solo un pasar.

\section{LOS NARRADORES}

En La nave de los locos, las voces narrativas se definen por los objetos sobre los cuales giran sus discursos. Así, tenemos un narrador básico -que llamaré Narrador (I)- de características bien definidas, al que podríamos llamar el "lector cautivo" de Equis, por su proximidad a este personaje. Este narrador aparece comprometido con las alternativas del periplo de Equis aun cuando

22 "Los atributos que se adscriben a una persona la definen y la colocan en una posición particular. Al asignarle esa particular posición, las atribuciones "la ponen en su lugar" y, de esta manera, tienen, de hecho, la fuerza de imposiciones" (Laing 145). 
no lo perciba como una totalidad. Sus lagunas en este sentido son llenadas por una voz narrativa de mayor grado de conocimiento (Narrador II), que convoca y organiza discursos de diversa procedencia en un afán contrastante. Esta es la voz que contextualiza las peripecias de Equis, focalizando incluso su "interior", sus fantasías y sueños; es ella quien asiste a la metamorfosis de conciencia que sufre el personaje, aunque éste no saque las consecuencias ideológicas del caso. Finalmente, tenemos a una entidad "macro" (Narrador III) que enmarca la totalidad del relato corrigiendo y/o complementando a las otras voces. Es esta entidad la que dispone el texto en secuencias de viaje (y de doble vínculo) que cobran un valor diverso por contigüidad con fragmentos de otros textos y discursos, o enfoques del Tapiz de la Creación.

Factor común a estos tres narradores es su gesto intencional de abrazar totalidades o sistemas completos que, inevitablemente, terminan por escapárseles. En el caso de Narrador (I), el viaje y proceso de Equis aparece como una forma recurrente y cerrada, sin profundidad alguna, una secuencia fusionada con espacios y tiempo continuos: "Su viaje nunca terminado (llamado también el viaje incesante, la gran huida, la hipóstasis del viaje)" (Peri Rossi 33) Aquí, el sujeto se halla atrapado todavía en el doble vínculo, generado para su desgracia, por el mandato de descripción. El rompimiento de la circularidad del viaje aparece recién en el discurso del Narrador (II), cuya perspectiva funciona como una metapauta que contextualiza el viaje de Equis en el marco de otros viajes (el del excéntrico Morris, desde el contorno hacia el centro, por ejemplo). El efecto inmediato de esta contextualización es una profundización y diferenciación en el proceso de Equis, el que, sin embargo, no es presentado en todas sus partes (pues falta la etapa última de la re-realización, posterior a la resolución del enigma).

Mérito importante de este Narrador (II) es su acceso al subconsciente de Equis (si se puede decir que un personaje de novela tenga subconsciente). Asistimos así a la reelaboración del mandato primario en enigma, forma cognoscitiva que rompe un orden (matar al rey) ${ }^{23}$ al ser descifrado, y que otorga una nueva vida al que lo descifra. Sin embargo, la resolución del enigma no completa el viaje de Equis, sino que, más bien, lo traspasa a un nivel aún más abstracto. Nada sabemos de la nueva naturaleza y de la nueva

23 No me detendré a analizar la figura simbólica de "matar al rey". Sin embargo, me parece evidente que está relacionada con la fantasía social dominante, llámesela patriarcado, capitalismo, logocentrismo. 
perspectiva de Equis, luego de romper el doble vínculo, aceptándose como sujeto sexualmente impotente. No se sabe si una tal situación pueda ser evocada a través del lenguaje. Con todo, la incompletitud de esta secuencia aparece conjurada por la contextualización debida a Narrador (III) (entidad supra-narratorial que, movida por un afán racional, se decide a enmarcar, en un segundo grado, la secuencia del doble vínculo de Equis). Este enmarcado, como ya lo hemos dicho, se actualiza por un procedimiento de contigüidad. Los principales eslabones de este procedimiento son las diferentes partes del Tapiz de la Creación: Así, personajes marginales como Lucía, Morris, la adolescente Graciela, el astronauta Gordon, el efebo Perceval, encuentran su lugar simbólico en el Tapiz de la Creación. Sin embargo, esta meta-meta-pauta, de por sí incompleta, no garantiza la inserción del sujeto en un mundo estable. La legalidad de mundo ${ }^{24}$ teocrática y medieval, que el Tapiz representa, ha perdido su vigor, está arruinada; la novela se cierra constatando la ausencia de fragmentos importantes, entre ellos, los ríos de Paraíso. El Narrador (III), por lo tanto, confirma la obsolecencia de una legalidad de mundo que ha cedido al arruinamiento, la fragmentación y la orfandad de las criaturas. Pero algo nos dice sobre el sentido de sus viajes.

La intención de este Narrador (III) ha sido profundizar los sentidos latentes en cada parte de las secuencias de viaje (de Equis, de Morris, de las mujeres abortadoras, de Percival hacia el África) de acuerdo a alguna clave presente en el Tapiz. Ahora bien, independientemente de las sugerencias que surjan del estudio de la contigüidad de mundos, se debe observar el carácter inconcluso y fragmentario de esta meta-meta-pauta que pretende ser el Tapiz. No solo su descripción es parcelada por el foco de la mirada que lo recoge, sino que su aparición al interior del mundo evocado por el Narrador (II) es igualmente discontinua. Propuesto como metáfora de orden y lugar habitable, su validez como estructura deductiva y centrípeta aparece relativizada no solo porque

24 Empleo el concepto de "legalidad de mundo" en el sentido en que lo plantea el investigador Cedomil Goic, es decir, como aquella representación ficcional y autónoma de leyes o causalidades que rigen el mundo representado al interior de la obra literaria, es decir, el principio organizador general, que puede o no coincidir con las leyes físicas o sociales que rigen el mundo real. Legalidad de mundo, en la hermenéutica de Goic, está relacionada con los contenidos del mundo narrado y la estructura interna que da forma a este mundo. La transformación radical en el paso del realismo al irrealismo es un cambio profundo en la imagen de mundo que representa el texto y la legalidad interna que lo sostiene como objeto autónomo. Ver Cedomil Goic, La novela chilena, los mitos degradados. 
en sí misma es una estructura mutilada, sino porque su combinación con las pautas de los mundos (I) y (II) no alcanza a generar una nueva forma o Gestalt. El texto se cierra, así, con un doble final abierto: las partes que faltan del Tapiz y el escamoteo de la nueva conciencia del protagonista.

Pese a esto, no se debe subestimar el efecto de "paralaje paródico" que por contigüidad de secuencias genera el Tapiz. Así, resulta en extremo efectiva la mostración del Pantocrátor como centro irradiador de sentido y su contraste con el extravío y aislamiento de criaturas en circunstancia como la desdichada Kate, la suicida de Nueva York (Peri Rossi 70). Del mismo modo, un nuevo sentido se genera al contrastar la perfecta "cadena del ser" (Bateson) representada en el Tapiz, con la naturaleza alternativa que el hombre ha edificado en la ciudad (la metrópoli, Albión, ciudad evitable y, al mismo tiempo, centro de atracción). Pero, como ya he expresado, ninguna de estas profundizaciones, si se me permite la expresión, sobrepasa los niveles anteriores para constituirse en contexto absoluto. Se cumple así el diagnóstico de Gregory Bateson, según el cual nuestro conocimiento de lo real posee un carácter altamente conjetural, fruto del "roce" o contigüidad de percepciones que se homologan (Percival como un nuevo Adán que evoca su ambiente original) o se refutan (el movimiento constante de la Creación versus el viaje inmóvil, circular, en el que están atrapados la mayoría de los personajes, incluido Equis hasta el momento de romper el doble vínculo), sin lograr superar su carácter parcial y sin fundirse una con otra para constituir una nueva pauta.

En resumen, se puede decir que la naturaleza de las objetividades evocadas por los tres narradores aparece como instancias intersectantes en diferentes niveles, cuya jerarquía, propuesta por el Narrador (III), no posee la suficiente condición de totalidad modulante como para abrazar a las restantes en una estructura coherente. De la misma manera como los narradores conocen objetos comunes, pero sin conocerse entre ellos, las objetividades (el viajero, la ciudad, la proyección del Yo en el Otro) aparecen vislumbradas desde perspectivas tangenciales, que se tocan en un punto, pero que se separan en el resto de la trayectoria. El resultado de tal situación no es otro que la delegación de la iniciativa armonizadora (de la búsqueda de la comunicación directa) en un lector ideal, cuyo deseo se ve incitado y despertado frente a lo monumental de la tarea. Una sutil estrategia de la autora para remecer a su receptor, pues este debe llegar a descubrir que, para contextualizar definitivamente el mensaje de La nave de los locos, debe verse a sí mismo 
como sujeto conjeturable y conjeturado por otros, en círculos concéntricos y persistentes de vínculos inconscientes.

\section{EL DOBLE VÍNCULO}

El contexto de Equis es su propio viaje, un viaje impuesto, pero imposible de concluir por causa de una maldición original. Eva nace inscrita "en los conjuros tribales de la segunda naturaleza" (Peri Rossi 153). Ejerce la función de alta sacerdotisa, pero le está prohibido salir del mundo. Morris es el coleccionista por excelencia, el aplicador de meta-pautas al interior de órdenes ya fijados. Es un viajero inmóvil que busca organizar el caos desde el margen. Perceval es el evocador y nominador de su propio contexto (como Adán), pero en el fondo es un niño precoz que vive inmerso en sus fantasías edípicas. Gordon aparece atrapado en un ambiente que lo habita espiritualmente, pero que lo rechaza corporalmente (la Luna); ha llegado donde otros hombres no han llegado, pero no puede volver, convirtiéndose en exiliado radical de un mundo alterno. Las mujeres abortadoras llevan como un estigma su visita a Londres (otro nombre, por metonimia, para Albión), pues no pueden escoger otro destino: más aún, muchas vuelven a abortar. Graciela ha resumido la secuencia de su vida en los contenidos de su maleta de viaje; Glaucus, pasajero enfermo de la Nave de los Locos es la identidad complementaria de Artemius, y viceversa; el periplo de la nave misma es un viaje sin destino. Venecia, el Tapiz, una ciudad cualquiera con sus cines y campos de concentración, son estructuras que se abisman y se doblan sobre sí mismas, auto-contextualizándose y clausurándose como nomos ${ }^{25}$ de la modernidad. El ser solo alcanza su plenitud cuando la progresión de su existencia se integra a una realidad puntuada, a un script (guión) que lo acoge y le atribuye un rol dicotómico (víctima o victimario, hombre o mujer, natural o extranjero, escritor o lector), capturándolo en un mundo de atribuciones (por ejemplo, ser prisioneros, ser jóvenes) del cual no puede huir sin provocar una transgresión. La lógica de esta puntuación es excluyente; el sujeto mismo debe darse cuenta de ello. La secuencia de la vida no puede ser vivida desde dos perspectivas, y el revulsivo contra esta locura es la inducción (en dosis fuertes u homeopáticas) de discursos contradictorios. 
El resultado de la introyección del doble vínculo es la ansiedad, la neurosis $\mathrm{y}$, finalmente, la angustia. Algunos creen que el doble vínculo tiene, al fin y al cabo, un valor de supervivencia; sería notable descubrir que ya viene introducido en nuestros genes más íntimos y olvidados.

La nave de los locos es una puesta en escena de la pasión de los sujetos (y de esos agregados inconscientes, las sociedades) por auto-elucidarse en la asunción (inmolación, para algunos) de una identidad, un valor de función y una perspectiva. Su autora, sin embargo, se cuidó muy bien de combatir esta ideología (ahora sí, en su sentido perverso) con otro discurso totalizador. Su crítica, de todas maneras, es nostálgica e idealista (en su sentido superior). Las personas no son formadas para gozar de mensajes plenos, de su producción y comprensión, ni se les enseña a producir su propia historia, fábula o guión. El efecto estético y desrealizador del pornoshow de Lucía radica en el caso de que está hecho de retazos de otros shows; es una puntuación de puntuaciones, una pauta en segundo grado, un híbrido. La sugerencia última de La nave de los locos viene a ser que la escalada de narradores debe continuar "su intrincado destino en la conciencia del lector" (Borges) ${ }^{26}$. Lo mejor que podría pasar (parece ser el mensaje de Cristina Peri Rossi) sería que no nos empeñásemos en completar el Tapiz, sino que proyectáramos sobre él otra pauta tentativa, algo no presentable o atribuible, sino más bien íntimo: una expansión de nuestros museos interiores.

Como dije en la introducción, una doble atadura es la consecuencia de la interiorización de mensajes contradictorios que afloran en conductas ostensibles, igualmente angustiantes. Pero la conciencia de estar doblemente vinculado es otra cosa. Es una situación de lucidez única, un punto de partida para el desmantelamiento de las "máscaras de cartón”, como diría el Capitán Ahab. Ahora bien, la noción de heterotopía ${ }^{27}$, que ha sido observada acertadamente (1968).

$27 \quad H e$ aquí la clásica definición de Foucault: "There are also, probably in every culture, in every civilization, real places -places that do exist and that are formed in the very founding of society which are something like counter-sites, a kind of effectively enacted utopia in which the real sites, all the other real sites that can be found within the culture, are simultaneously represented, contested, and inverted. Places of this kind are outside of all places, even though it may be possible to indicate their location in reality. Because these places are absolutely different from all the sites that they reflect and speak about, I shall call them, by way of contrast to utopias, heterotopias". En: Michel Foucault, Of Other Spaces: Utopias and Heterotopias. En: http://web.mit.edu/allanmc/www/foucault1.pdf. Consultado en abril de 2017. 
por la crítica como un concepto clave de La nave de los locos, no es sino una de las dos condiciones tangenciales; la otra dice relación con la esencia del ensimismamiento melancólico, representado en la historia de Gordon. Las heterotopías serían, pues, mecanismos de defensa, tanto del Yo como del Otro, frente a la inducción del doble vínculo y su desmantelamiento. Ante estas absorbentes posibilidades, la resolución del enigma por parte de Equis ofrece una síntesis en un nivel superior: para superar la parálisis de su doble lazo, Equis "reescribe" el mandato original como enigma, jugándose el todo por el todo; ello le permite generar, en sueños, su propio paisaje (espacio habitable) en el que buscar y encontrar la respuesta. Como vasos comunicantes, el sueño y la vigilia se conectan; es en su desairada entrevista con una prostituta (en la que rompe con una pauta de interacción, al reconocer su impotencia sexual) cuando empieza a vislumbrar la respuesta. Luego, tenemos el espectáculosíntesis de Lucía y la dádiva de la respuesta entregada por ella, nuevamente, en el sueño. Aquí se produce, paradójicamente, el desalojo y arrasamiento del campo de concentración, el nomos del doble vínculo ${ }^{28}$.

Se oyen truenos, relámpagos alados cruzan el cielo, una pesada piedra cae y abre el suelo, animales extraños huyen por los cerros... (Peri Rossi196-7).

Hay que entender que la superación del doble vínculo espacio-temporal pasa por la creación y destrucción constante de lugares habitables (reales o imaginarios, representados o fantaseados), y, con ello, la validación y desautorización perpetua de nuestro Yo como autoimagen inmóvil, centrada y asentada en firmes coordenadas y discursos: Una reconstrucción de personalidades arruinadas.

28 "Es menester reflexionar sobre el estatuto paradójico del campo de concentración en cuanto espacio de excepción: es una porción de territorio que se sitúa fuera del orden jurídico normal, pero que no por eso es simplemente espacio exterior. Lo que en él se incluye, es, según el significado etimológico del término excepción, sacado afuera, incluido por medio de su propia exclusión". Cito por Giorgio Agamben, "El campo de concentración como nómos de lo moderno. En: Iván de la Nuez, ed. Paisajes después del Muro. 


\section{CONCLUSIONES}

Una lectura atenta de la obra de arte literaria absorbe, necesariamente, la lectura misma en el contexto de las percepciones de nuestro entorno, que incluye obras de arte y comportamientos creativos. Absorbe o incorpora las lecturas psicológicas y culturales en los estados individuales, grupales o sociales de construcción de realidad. Implica al sujeto lector mismo, embarcado en esa metáfora de la lectura que es viaje mismo ${ }^{29}$.

Debo reconocer, llegado el momento de la evaluación, que mi hipótesis se sustenta sobre el siguiente presupuesto: la literatura, además del goce estético, provee una mayor comprensión de algunos fenómenos esenciales de la interacción humana. En este sentido, he tratado de probar que La nave de los locos planteaba de manera implícita y formalmente acabada el asunto del "doble vínculo", tanto en el nivel de la enunciación (proponiéndonos estos narradores superpuestos y entrecruzados, animados por el mismo deseo de naturalizar la contradicción como totalidad) como en el de la historia (estos viajes circulares que se rompen, finalmente, viviendo la experiencia del contorno, del desvío, que conduce a la revelación) y de las relaciones de los personajes con el espacio y el tiempo (a través de estas introyecciones, expansiones y desalojos heterotópicos). El resultado final de mi lectura arroja que se puede vivir durante un tiempo indefinido una situación de doble vínculo, pero es deseable hacerla consciente para superarla hacia un nivel ulterior de conciencia. Cómo sería este nuevo estado, La nave de los locos apenas permite vislumbrarlo, de lo que concluyo que el objetivo específico del texto era presentarnos las múltiples situaciones y los diversos discursos y pautas que amenazan con (y a veces consiguen) atraparnos dentro de un sistema de fantasía social. Demostración efectiva, como se ha visto, que asume, siguiendo a William Blake, la forma del trazo de un contorno hecho por mano sabia. Y que, como opina Juan Emar, atrapa en su interior un conjunto de experiencias que el lector reproduce en abismo, con gran fruición y beneficio para él y su espíritu.

29 Sobre la relación entre lector real y el espectador implícito, como una de las múltiples sugerencias y problematizaciones de esta novela, ver el excelente artículo de Lucía Invernizzi Santa Cruz, "Entre el tapiz de la expulsión del Paraíso y el tapiz de la creación: Múltiples sentidos del viaje a bordo de "La nave de los locos" de Cristina Peri Rossi", En: Revista Chilena de Literatura 3, 1987. 


\section{BIBLIOGRAFÍA}

Bateson, Gregory. Espiritu y naturaleza. 3a. ed. Buenos Aires: Amorrontu, 2011.

Campbell, Joseph. El héroe de las mil caras, psicoanálisis del mito. México: Fondo de Cultura Económica, 1959.

Cano, Marcel et al. "La Weltanschauung (cosmovisión) en el comportamiento medioambiental del siglo XXI: cambios y consecuencias.” Ludus Vitalis Vol. XVIII, No. 33 (2010): 275-278.

Cordella, Patricia. "Qué es semiosis". Revista Gaceta de Psiquiatría Universitaria Vol. 10, No 4 (2014): 390-394.

De la Nuez, Iván. Ed. Paisajes después del Muro. Barcelona: Península, 1999.

Foucault, Michel. Of Other Spaces: Utopias and Heterotopias. Recuperado de: http://web. mit.edu/allanmc/www/foucault1.pdf

Gratacòs Lamberto Font. "El tapiz de la Creación de la Catedral de Gerona: ensayo de estudio para una monografía". Recuperado de: http://dugi doc.udg.edu/bitstream/ handle/10256/5970/53330.pdf? sequence $=1$.

Hidalgo, Juan Cid. "Exilio y migración en La nave de los locos de Cristina Peri Rossi. Un viaje por los espacios otros.". Co-herencia Vol. 9, No 17 (julio-diciembre 2012): 51-70.

Invernizzi Santa Cruz, Lucía. "Entre el tapiz de la expulsión del Paraíso y el tapiz de la creación: Múltiples sentidos del viaje a bordo de "La nave de los locos" de Cristina Peri Rossi". Revista Chilena de Literatura. Vol. 3 (1987): 29-53.

Laing, R. D. El yo y los otros. México: Fondo de Cultura Económica, 1985.

Parrilla, Desiderio. "René Girard y la teoría del doble vínculo de Palo Alto". Revista de Filosofía. Vol. 2 (2015): 109-126.

Peri Rossi, Cristina. La nave de los locos. Barcelona, Seix Barral, 1989.

Richards Varas, Constanza. "La desmitificación del tópico del amor en La nave de los locos". Tesis de Grado. Universidad de Chile, 2014.

Rodríguez-Zoya. L. G. y P. G. Rodríguez-Zoya. "El doble vínculo entre representaciones sociales y comunicación social." Palabra Clave. Vol. 18, No. 3 (s/d): 905-937.

Spengler, Oswald. La decadencia de Occidente. Madrid: Espasa Calpe, 1976.

Valdivia, Cristina. "La presencia del mito del andrógino en La nave de los locos de Cristina Peri Rossi". Anuario de Pregrado Universidad de Chile 1 (2004): 1-19.

Watzlawick, Paul. La realltá della realltá. Confusione, disinformazione, comunicazione. Casa Editrice Astrolabio, 1976. 